\title{
DID GREEK DRAMATISTS WRITE STAGE INSTRUCTIONS?
}

There is no agreement on the answer to this straight and modest question of textual history. ${ }^{1}$ As representative of one extreme I may cite Page's excursus in Actors' Interpolations ${ }^{2}$ : note 'the prompt-copy must certainly have contained (among other notes) stage-directions'. He and his allies clearly imply that the original text, whether the dramatist's autograph or some contemporary fair copy, was covered with dozens indeed hundreds - of stage directions, and that for some reason they were all but eliminated in the course of transmission. For the opposite view I quote David Bain's new book: 'Such marginalia as we have are for the most part reader's additions and do not constitute part of the paradosis'. 3 In favour of this side is the absence from our texts of all but a handful of the thousands of possible stage directions: on the other hand there is just that smattering in both tragedy and comedy, and they have to be explained.

The bulk of this paper will be taken up with a full survey of all those places I know of where a stage instruction has either definitely or allegedly been transmitted in our texts of Greek tragedy and satyr play. This restriction of scope calls for some preliminaries. First, I shall not be covering comedy in the same detail; but I am confident that in this respect the textual history of both genres is the same, as I shall argue briefly in section iii. A point worth making here is that the word $\pi a \rho \epsilon \pi \iota \gamma \rho a \varphi \eta$, which was evidently the Greek for a stage instruction, while it is used occasionally in connection with tragedy, is far more often applied to

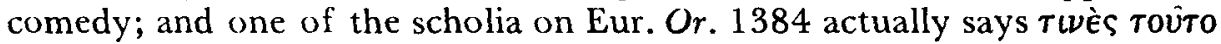

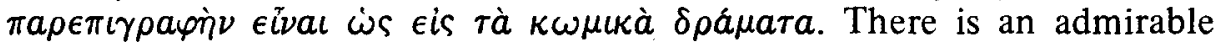
account of the word's range of usage in Rutherford 113-14.

Next I put on one side the class of stage direction which is by far the most common and the most important: the attribution of parts to speakers. My reasons for by-passing these are that they make a distinct class to themselves and that they have been excellently discussed by Andrieu and Lowe. ${ }^{4}$ The outcome of their studies is put clearly by West (Textual criticism and editorial technique (1973) 55): 'the attribution of a speech to such-and-such an interlocutor rests on no tradition that reaches back to the author... but only on later interpretation.' This conclusion has not, so far as I know, been seriously challenged and I do not see how it can be. This is, then, an initial pointer for the question of 
my title, and it favours Wilamowitz u. dgl. as opposed to Page and co.

Lastly, however, I come to another special class which may well, on the contrary, go back to the author or a contemporary copy - the inscription

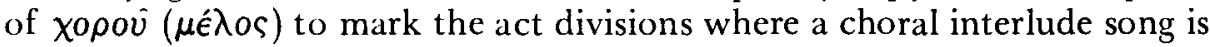
to be supplied by a $\chi 0 \rho o \delta\llcorner\delta a \sigma \kappa a \lambda o s$ independent of the poet. This is found mainly, of course, in late Aristophanes and later comedy, but there are also two or three tragic instances in anonymous papyrus fragments. I have discussed these in Liverpool Classical Monthly 1 (1976)47-50 where I see no reason to doubt the usual view that the author himself signalled these junctures. But these are a rather different kind of stage direction from those under discussion here, and in any case they are not - or so I argue in that note - to be found before the very end of the fifth century.

After these circumspections I come to my critical catalogue of parepigraphai, real and illusory. I do not suppose it is complete - there is a mere baker's dozen - but I know of no other systematic attempt to compile one.

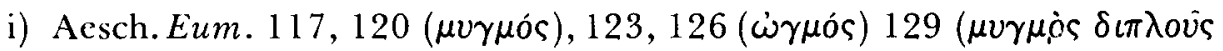
ózús).

First the most conspicuous as well as the most blood-curdling instance in ancient drama, actually called $\pi a \rho \epsilon \pi \iota \gamma \rho a \varphi \eta$ by the ancient scholion on 117 , and perhaps the strongest candidate of all to go back to the dramatist himself. 5 But before jumping to conclusions it should be noticed that any careful reader can work out that there must be noises from the Erinyes in between each couplet, and he could supply the nouns from $\mu \dot{v} \zeta o i \tau^{\prime} a{ }^{\prime} \nu$ in 118 and $\ddot{\omega} \zeta \epsilon \iota s$ in 124 . Another point which suggests scribal activity is that interjections and non-verbal utterances when they are supplied at all, whether in tragedy, comedy or satyr play, whether delivered on-stage or heard from off-stage ${ }^{6}$, are normally written out phonetically -

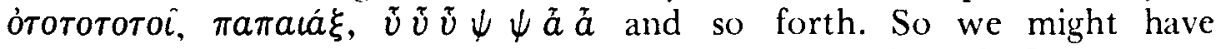
expected Acschylus to write out the Erinyes' noises $(\mu \bar{v} \mu \bar{v}, \dot{\omega} \dot{\omega}$ ctc., cf. Ar. Knights 10); and these nouns in our text may have been substituted by a scribe for the purpose of brevity or calligraphy. What does not seem so easily explicable is $\mu v \gamma \mu \grave{o} \varsigma \delta\llcorner\pi \lambda o v \varsigma$ ó $\xi u s$ in 129 . Yet this is also the most suspect of the five parepigraphai since at this point Aeschylus has actually supplied the words of the dreaming chorus: $\lambda a \beta \dot{\epsilon}, \lambda a \beta \dot{\epsilon}, \lambda a \beta \dot{\epsilon}, \lambda a \beta \dot{\epsilon} \cdot \phi \rho a \dot{\zeta}$ \}ov. Is the parepigraphe meant to come before those words, or at the same time, or to be a substitute for them? Again it seems possible that this is a piece of tidying up (derived perhaps from some marginal note) by a decorous scribe offended by a string of hunting cries in a tragedy. ${ }^{7}$ So, 
while I do not deny that these parepigraphai might go back to Aeschylus, that is not the only possible explanation.

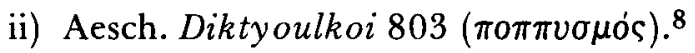

The popping noise is probably meant to be made by Silenus in an attempt to cheer up and win over the infant Perseus. Compare

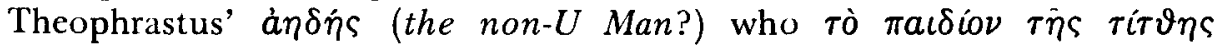

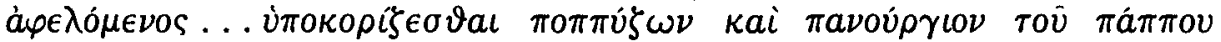
$\kappa a \lambda \omega \nu$. The onomatopoeic noun is just like the Erinyes' parepigraphai; but it does not seem inferable from the text and looks at first sight as though it must go back to Aeschylus. On the other hand would not he have written the noise out phonetically? Our texts of satyr plays, especially Soph. Ichneutai, are full of weird noises which are spelt out in full. So again we may alternatively have a reader's addition (taken from marginal notes?) or a scribe's replacement for what Aeschylus actually wrote.

iii) Aesch. Seven against Thebes 84, 89 ( $\beta$ ố).

This double $\beta o \hat{a}$ is hard to accommodate to sense and metre, and Murray $O C T$ suggested that both are parepigraphai (viz. Boâl). It is not clear whether these would refer to noises off stage or to noises by the chorus (in which case one would expect the interjections to be spelt out in the usual way); in either case it is odd that the stage direction should be doricized. It is much more plausible to deal with both by emendation.

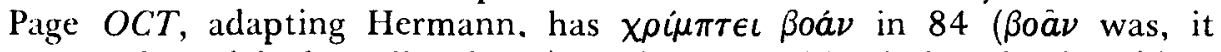
seems, the original reading in $M$ ), and accepts Maas's interjection óa in 89.

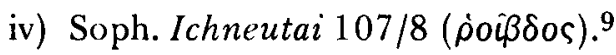

It is pretty clear that the scribe of our papyrus (POxy 1174) thought of this whirring or swishing noise as a stage direction; and it is, I think, no less clear that he was mistaken. The parepigraphe is taken to refer to a noise off stage, either the lowing of the cattle (e.g. Robert) or the sound of the lyre (e.g. Grenfell-Hunt, Pearson). But both are out of the question at this particular place. It is fairly clear that in 107 one hemichorus tells the other to listen out for any noise ( $\dot{\rho}(\beta \delta \eta \mu a)$, and in 108-11 the other replies that it can not hear anything; then in $111 \mathrm{ff}$. the hunt intensifies as the reversed hoofprints are discovered. So the noise of cattle is out of place. The noise of the lyre is also ruled out by the larger context. ${ }^{10}$ It is clearly at 124 that the lyre is first heard from within, and again at 136 (though there is no parepigraphe at either place). The satyrs are, as usual, terrified by their first encounter with a discovery which will turn out to be a great benefit; 11 and they flee (see lines $160 \mathrm{ff}$.). But Silenus does not hear the noise and acts the gloriosus, until the lyre rings out again at 197 (no parepigraphe); this time he does hear, and at 203 he flees 
ignominiously. 12 So there is no place for the lyre at 107/8: it is first heard at $124 / 5$ and several times after that. How, then, did the parepigraphe get there? Fortunately, it is easy to see from the papyrus itself. $^{13}$ In 1.107 there was some form of pou $\beta \delta$ - which was twice corrected. It is likely there was some confusion in the scribe's exemplar also, and either he or an earlier copyist wrote out what was meant to be a gloss or a correction as an interlinear parepigraphe. ${ }^{14}$

v) Soph. Phil. 787 ( $\pi \rho \circ \sigma \epsilon ́ \rho \pi \epsilon \iota)$.

In these Proceedings n.s. 14 (1968) 17 R.D.Dawe objects to $\pi \rho 0 \sigma e ́ \rho \pi \epsilon \iota$ in the mouth of Philoctetes and suggests that it is a parepigraphe. His complaint is that the word 'disturbs the iambic flow of the passage'. But it is characteristic of Sophocles' fluid dialogue technique, especially in the last plays and especially at moments of high pathos, that he introduces isolated iambic metra, often catalectic. The phenomenon could hardly be more firmly established than by Fraenkel's note on Aesch. Agam. 1216: compare especially Phil. 219, $750, O C 315,318,1271$. Its purpose is precisely to disturb the flow of the trimeters. $\pi \rho 0 \sigma \epsilon \cos \epsilon$, which makes sense when it is glossed by the following line, is related in emotional function to the cries of pain in 785, 790 and 796 and to the $\tau i \varphi$ ís, $\pi a i$; in 804 . Dawe would also like to do away with 804 as a 'paraphrase' (sic) of 805. But it is closely parallelled by the agonized 'monometer' of

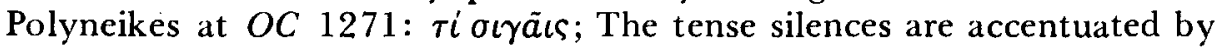
the disturbance of the stichic regularity. But while $\pi \rho 0 \sigma \epsilon \rho \pi \epsilon \iota$ is admirable Sophocles in the mouth of Philoctetes, it would not be beyond objection if it were a parepigraphe. It is not closely related to the text and the significance of this poetic world would be far from clear - who crawls toward whom? If it were the work of Sophocles it would be unhelpful to readers; also it would imply that his text was covered with hundreds of notes indicating every smallest gesture. Why should this one happen to survive? If, however, we are to suppose it is the addition of a reader or scholar, then, since it is not indicated by the text, we should take it simply as an error based on a misunderstanding of the following line.

vi) Eur. Cycl. 487 ( $\dot{\iota} \iota \grave{\eta}$ ě $\nu \delta o \vartheta \epsilon \nu)$.

This instruction for the supply of a sound which is clearly implied by the text is closely paralleled from the manuscripts of comedy: Ar. Birds 221 , Frogs $311 / 2$, cf. Frogs 1263 , Men. Dysc. $879 / 80$. It is also obviously comparable with (i) and (ii) above. It might go back to Euripides; but it is also quite possible that it was in origin a reader's addition.

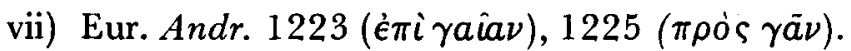

There is no metrical equivalent to either phrase in the strophe. Page 65 (cf.115) comments laconically 'may possibly contain incorporated stage- 
directions'. But not only are they poetic formations, but also as stage directions they would be pointless: if at 1223 Peleus throws his sceptre away it must fall to the ground, and if at 1225 he falls then it must be earthwards. This is admittedly an awkward pair of textual problems, but I rather think that Hermann was along the right lines in both places. At

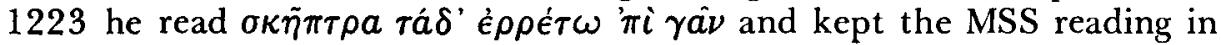

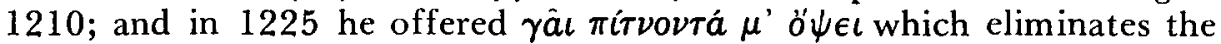
peculiar ö $\psi \epsilon a$ c. Whatever the truth, it is surely not a matter of parepigraphai whether author's own or later.

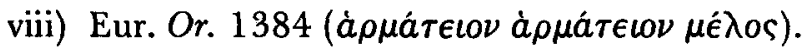

The words make good sense in their context, and no modern scholar would have dreamt that they might be an intrusive parepigraphe were it not that the scholiast tells us that a certain Apollodorus of Cyrene held them to be a musical instruction indicating the use of the à $\rho$ átelos vómos. Some, including Murray, have believed him. ${ }^{15}$ But the scholiast

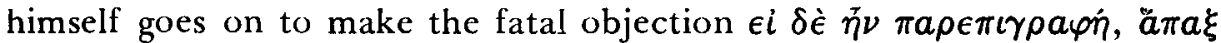

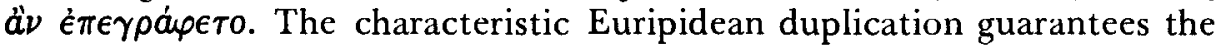
text as part of the Phrygian's aria. ${ }^{16}$ Apollodorus is no better than the scholiast (in R) who claimed that $\sigma \pi 0 \nu \delta \dot{\eta} \sigma \pi o \nu \delta \dot{\eta}$ at Ar. Peace 1104 was a parepigraphe. There is no reason to regard him as anything but an overingenious bookworm ready to resort to any absurdity in order to get his name into a repertory of conjectures - successfully.

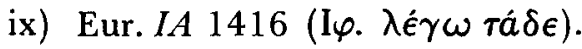

L's exemplar must have read simply $\lambda \epsilon \operatorname{\gamma } \omega$ tá $\delta \epsilon$ which he dutifully copied, though a later hand filled out what he took to be an incomplete line. Whatever the solution of this corruption, the claim, put forward by

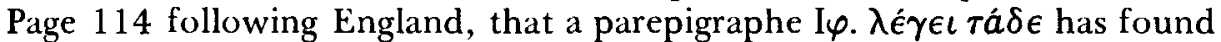
its way into the text is not likely. Changes of speaker were marked by paragraphos and/or double point, and later by marginal abbreviation of the speaker's name (see above); with these conventions to hand there is no reason why anyone should bother to write $\lambda \dot{\epsilon} \gamma \epsilon \iota \tau \hat{\tau} \hat{\delta} \epsilon$. In any case Page would not claim that his parepigraphe went back to the dramatist.

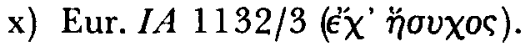

Page $i b i d$. detects another corrupt parepigraphe - iov́ $\chi \omega \varsigma$ - in the text here on the ground that 1132 must be spoken aside, and hence that '́ $\chi$ ' $\ddot{\eta} \sigma v x o \varsigma$ must be corrupt. But, even though the Bodmer codex of Men. Aspis has produced two instances of $\dot{\eta} \sigma v \times \hat{\eta} \iota$ as a stage direction, that does not make Page's case any less weak. I have nothing to add to the

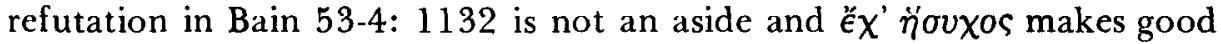
sense, though not good Euripides. Moreover there is reason to doubt that 
the parepigraphai in Aspis go back to Menander, since, while that on 467 is fair enough (see Bain 106-8) that on 93 is clearly wrong (Bain 132-3): this suggests that both are the work of annotators.

xi) Anon. Rhesus 17 (oủk ëorl).

As transmitted 16-17 read:

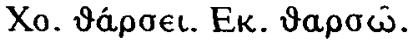

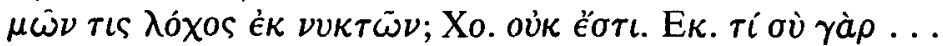

For any editor of Euripides the antilabai within anapaestic metra and the metre of 17 will be most distressing. Most since Dindorf have cured 17 by cutting out ovk éor $\iota$ and hence the interruption by the chorus; and Murray

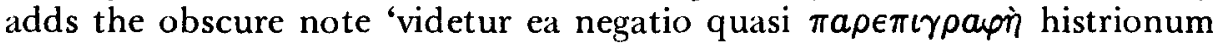
monendorum causa adscripta fuisse'. This would be quite unlike any other parepigraphe, and would be very odd even in an ordinary scholion.

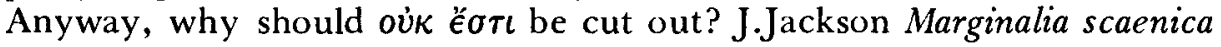
(1955) 12 keeps it and restores the metre by a simple emendation:

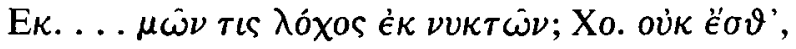

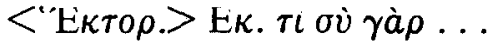

In that case it is not a matter of a parepigraphe intruding into the text, but of part of the text getting incorporated into the attribution of speakers. This seems very plausible. But if it is right then we have a third change of speaker within a metron to add to the diaeresis between $\dot{\epsilon} \kappa$ and $\nu v \kappa \tau \hat{\omega} \nu$ and the close similarity of line 16 to Anon. $I A$ 2-3, making no less than five un-Euripidean features in two lines. ${ }^{1} 7$ Ritchie The authenticity of the Rhesus of Euripides (1964) 290-1 is in desperate straits. He has to argue that these confusions and interruptions betray the deep corruption of an innocuous Euripidean text. But the confusion and interruption are a deliberate, and quite successful, attempt to convey midnight alarums on the stage. In fact this dramatist is something of a specialist in the realistic presentation of ignorant armies clashing by night, as may be seen especially in the sequence at $674 \mathrm{ff}$.

xii) Carcinus Aias $\operatorname{Tr} G F 70 \mathrm{~F}$ la (risit).

Snell prints '(risit)' as part of the fragment, as though it were a parepigraphe. But the anecdote in Zenobius seems to say that this

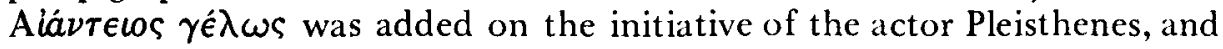
was not the work of Carcinus himself. So it would not be an author's

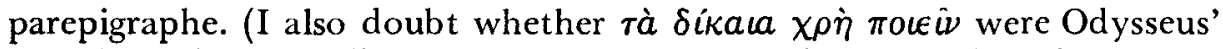
actual words, as Snell supposes: in that case we have a testimonium, not a fragment.)

xiii) Trag. Adesp. POxy 2746 lines 3, 9, 12, 15, 22, 26 ( $\dot{\omega} \iota \delta \dot{\eta})$.

This curious fragment was published and discussed by Coles in BICS 15 
(1968) $110 \mathrm{ff}$. As possible explanations of the interlinear $\omega \iota \delta a i$ Coles considers interlude, accompaniment, manner of delivery, improvisation and he points to the difficulties of each of these. He does, however, neglect one important point: in each case $\dot{\omega} \iota \delta \dot{\eta}$ is followed by an indented half-line, even though this sometimes appears to be the first half of a trimeter. While this may be purely calligraphic, it may suggest, since eisthesis is normally a sign of lyric, that each line immediately after an $\dot{\omega} \iota \delta \dot{\eta}$ should be sung. The piece appears to be inspired by the Cassandra scene in Aesch. Agam.; and this may be a rather clumsy attempt to reproduce the 'epirrhematic' effect of alternating speech and song. The fragment may be some curiosity of amateur dramatics rather than the text of a proper tragedy; and nothing much can be based on its peculiar parepigraphai.

To pull together this survey in relation to our initial question: of the thirteen candidates for authentic parepigraphai seven (iv, v, vii, viii, ix, xi, xii) are almost certainly the fabrications of pedants, ancient or modern, and so are two others (iii, $\mathrm{x}$ ) more likely than not. That leaves just four the Erinyes' noises in Eum., Silenus' labials in Diktyoulkoi, the singing from Polyphemus' cave in Cycl., and the strange 'songs' of the strange Cassandra fragment (which does not really count) - just four which might well go back to the dramatist himself. In each case I hope to have shown that this is not the only possible explanation.

All four are, of course, aural; they all direct sounds of one sort or another, whether on or off stage. We might be tempted to argue that, while the dramatists did not add any other kind of stage direction, such as gestures or costumes, they did indicate noises. The great objection to this is that there are many places where noises which are clearly inferable from the text are not indicated explicitly, neither by phonetic transcription nor by a parepigraphe. A few examples are the trumpet at Aesch. Eum. 573, the lyre in Soph. Ichneutai (see above), the approach of Philoctetes at Phil. 201ff., the distant sound of the murder at Eur. El. $747 \mathrm{ff} .^{18}$ So it is surely a much more likely hypothesis that the convention arose that keen readers might, if they liked, write in their own parepigraphai indicating any noises they thought they could infer from the text; especially since it has now been shown that a convention of this sort grew up in the matter of the attribution of parts (see above). This would explain why such parepigraphai survive at random and why some are demonstrably wrong. 
The parepigraphai of comedy do not contradict this thesis. I have already referred to several which indicate noises and asides. A curiosity

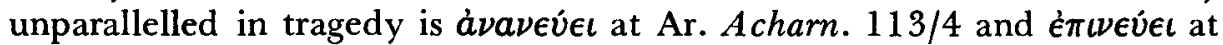
$114 / 5$ referring to the nodding of the King's Eye, both clearly right and clearly inferable from the text. Another is the POxy 211 fragment of Men. Perikeiromene (lines $976 \mathrm{ff}$. in Sandbach), where three exits and entrances are written in the text: few would claim, I think, that these go back to Menander rather than to a later acting copy. ${ }^{19}$

Nothing inexplicable so far. But there are two parepigraphai, both in Ar. Thesm., for which it is claimed that it is difficult to see any other source ... than a very early copy of the play in which the dramatist's intention was preserved'. 20 At the end of Agathon's display of lyric virtuosity the text has $\dot{\lambda} \boldsymbol{\alpha} \lambda \dot{v} \zeta \epsilon \iota \dot{o} \gamma \in \dot{\epsilon} \rho \omega \nu$ before the beginning of the old boy's ecstatic speech (130ff.); and at $276 / 7$ we have (after emendation)

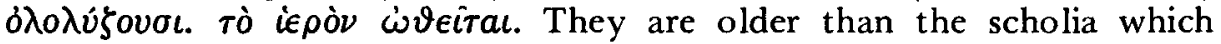
comment on them as $\pi a \rho \epsilon \pi \iota \gamma \rho a \varphi a i$, and the second, at least, older than PSI 1194.21 But the second is also more suspicious, especially the instruction that the sanctuary should be thrust out on the ekkyklema. Directions for the use of this contraption - some probable, some possible, and some out of the question - are preserved all over the place in our scholia. Is it not likely that this note (which does not seem to me to be correct beyond all doubt) has been transferred from a marginal annotation? Secondly, what of the direction that the women raise an $\delta \lambda o \lambda v \gamma \dot{\eta}$ at this point? In 277-8, before he beats it, Euripides says:

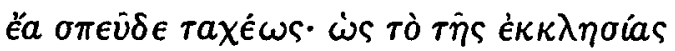

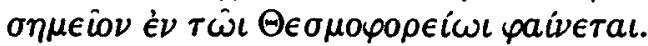

Apparently we do not know what the signal for the gathering of the

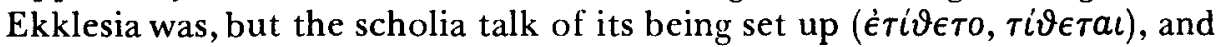
we gather from Andoc. Myst. 36 that the signal of the Boule could be taken down ( $k a \vartheta \epsilon ́ \lambda o \iota)$. The audible proceedings of the ThesmophoriaEkklesia begin at line 295, and it seems that in $277 \mathrm{f}$. Euripides is alluding to a visual signal, whether it was seen in the theatre or left to the

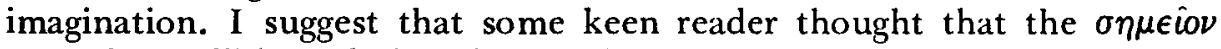
must be audible and thought an ololygmos appropriate; his annotation then found its way into the text.

And $\delta \lambda o \lambda u ́ \zeta \epsilon \iota \dot{o} \gamma \in \hat{\epsilon} \rho \omega \nu$ at $129 / 30$ ? It is a nice touch, and Aristophanes might have liked it (though the following lines suggest other more indecent stage instructions). But would he not have written it out phonetically? In 
view of all the other evidence, the finger points at our annotator again.

He lurks, finally, behind one more place early in Thesm. Agathon has been rolled out and Euripides hushes his irrepressible relative: oiya.

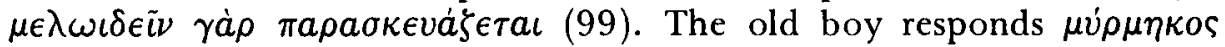

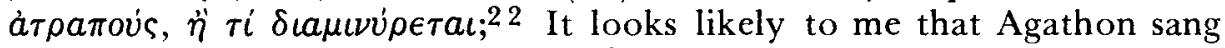
some practice trills or something of the sort. Our annotator thought so

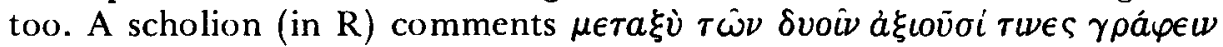

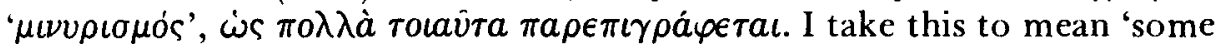
commentators think you should write $\mu \iota v v \rho \iota \mu \mu$ os as the usual sort of parepigraphe between the two lines'. This cannot be reporting a variant reading, it must surely be referring to an editorial decision of exactly the kind that has been posited. This scholion does not figure in most discussions of parepigraphai precisely because this particular one did not get accepted into the main textual tradition. Rutherford 105 scrupulously records it, and adds hastily 'but unhappily that comment almost awakes the suspicion that none of the six [other parepigraphai in Aristophanes' text] is necessarily primitive'. It does indeed awake that suspicion, and it casts it over the similar nouns in Eum. and Diktyoulkoi also. I suggest that it clinches the case that Greek dramatists did not write stage instructions, at least not explicitly.

\section{IV}

Had we reached the opposite conclusion there might have been interesting consequences not only for the place of parepigraphai in our texts and for the authority of our scholia on staging but also for the relation of the dramatist to his play - it would have given the author a scriptural rather than a theatrical role. What may be implied by our negative conclusion, other than the not inconsiderable editorial consequence that all transmitted parepigraphai should be relegated to the

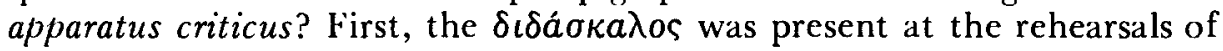
his plays and could teach his stage directions on the spot; so there was no call for him to write them down. The critical consequences of this theatricality are one of my major preoccupations in The stagecraft of Aeschylus (passim esp. 12-28). Another of the book's theses (passim esp. 28-39) makes my second implication: the Greek tragedians signalled all their significant stage directions in the words. This is on the whole true of comedy also, though there is a rather less close relation between text and performance, which may explain the association of commentators' parepigraphai with comedy.

Now, it might appear that these two hypotheses are incompatible: how can we claim both that the dramatists did not bother to write stage 
directions, regardless of readers, and that at the same time they obligingly implied all their directions in their words? I suggest that the way out of this apparent contradiction is that the close relation of text and stage action is only incidentally useful to readers, and was originally directed to the audience in the theatre. If some action (or sound) was to be significant, then the dramatist would spend time and words on it: he did not allow dialogue about other things to compete and he did not risk the unclarity of dumb-show. What calls for attention has attention drawn to it. This fits with the critical principle (which for myself $I$ associate especially with Eduard Fraenkel) that the meaning of Greek drama is in the open, not conveyed indirectly or to be read between the lines.

Greek dramatists did not write stage directions in the usual sense; but whenever any stage business was an important element in the play they reflected it clearly in the words. So too with all the vehicles of their meaning. Thus the pursuit of our modest question of textual history may corroborate a fundamental principle of dramatic interpretation.

MAGDALEN COLLEGE, OXFORD

O. TAPLIN

\section{NOTES}

1. There is a disconcertingly large bibliography for such a little subject. The following will be cited by author's name alone: J.Andrieu, La dialogue antique (1954). D.Bain, Actors and audience (1977). J.C.B.Lowe, 'The manuscript evidence for changes of speaker in Aristophanes', BICS 9 (1962) $27 \mathrm{ff}$. W.J.W.Koster, 'Ad Aristophanis Thesmophoriazusarum fragmenta in PSI 1194 servata', Acme 8 (1955) 93ff. D.l.Page, Actors' interpolations in Greek Tragedy (1934). W.G.Rutherford, A chapter in the history of annotation (1905). O.Taplin. The stagecraft of Aeschylus (1977). U. von Wilamowiť, Einleitung in die griechische Tragödic ed. 3 (1921).

2. Page 112-15; cf., for example, Wartelle, Histoire du texte d'Éschyle (1971) $323 \mathrm{ff} .$, Handley, The Dyskolos of Menander (1965) 48, 283.

3. Bain $53 \mathrm{n} .2$; cf. $18,132 \mathrm{f}$. The chief authority is Wilamowitz $125 \mathrm{f}$.; cf., for example, Andricu 188, Weissmann, Die scenische Anweisungen in d'n Scholien (1896) 21-31 esp. 22, Zwicrlein, Die Recitationsdramen Senecas (1966) 128 n.5.

4. Andrieu passim esp. 258-82, Lowe passim esp. 35-7. I add a few corroborative observations in Taplin 294.

5. Cf. Page 113, Dover, Aristophanic Comedy (1972) 10.

6. I argue that the Erinyes are in fact still inside the skene: Taplin 369-74.

7. For some hunting cries sec Xen. Kyn.6.17-20. 
8. While we wait for $\operatorname{Tr} G F$, reference to papyrus fragments of Aeschylus is becoming unwieldy. This is POxy 2161, fr.474 Mette, 275 Lloyd-Jones, pp. 62-4, 78 in the edition of Werre-de Haas (1961).

9. Pearson's line-numbers throughout.

10. There is a good discussion in E.Siegmann, Untersuchungen zu Sophokles' Ichneutai (1941) 58-60.

11. Cf. Taplin 420.

12. In 204-6 the satyrs are not speaking to Silenus, but are saying that they, unlike him, will stay. Hunt was unduly worried about the paragraphoi after 206 and 210 (ed.pr. p.76). They simply mark the parts of the two hemichoruses (or even, as Carden, BICS 18 (1971) 43-4 suggests, a change of metre).

13. See Siegmann (cited in n.10). Photo in POxy ix plate ii, and Turner, Greek manuscripts (1971) plate 34.

14. Andrieu 186 includes another fragment of Sophoclean satyr play in his discussion of parepigraphai: $P O x y 1083$ fr. $19=$ fr. 6.19 on p. 151 in Carden. But though written beneath the lines rather than in the margin this is evidently only an explanatory scholiastic note.

15. E.g.Page 114, Biehl, Textprobleme in Euripides Orestes (1955) 81-2, also in his commentary (1965) and text (1975). This obscure Apollodorus is no.62 in $R E I$ 2886. Murray even forgets his name and calls him Apollonius.

16. See Wilamowitz 125 n.5, Di Benedetto ad. loc.

17. On the diacresis see Barrett on Eur. Hipp. 1360; on Rhesus and $I A$ see Fraenkel, Gnomon 37 (1965) 235.

18. A fascinating instance with considerable consequences for the interpretation of the play is the thunder in Soph. OC. Did it first sound immediately after the Polyneikes scene at 1447 (thus e.g. Elmslcy) or at the end of the strophe at 1456 (thus e.g. Jebb)? I favour the latter because Oedipus should respond at once to the long-awaited sign (see 1.95), because the thunder calls for the clear language of 1456, and because that line, separated with asyndeton from the rest of the strophe, responds closely with 1471 ; cf. also the asyndetic $1485=1499$ - evidence perhaps for the musical use of tympani at the end of each strophe?

In that case 1447-55 are the chorus' response to the preceding scene and a guide to our feelings.

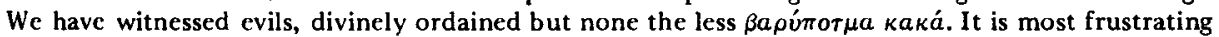
that when the key Sophoclean motif of xoóvos is introduced in 1453 we run into textual

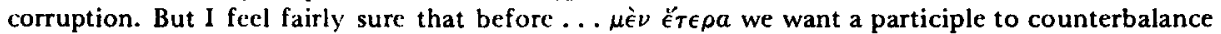

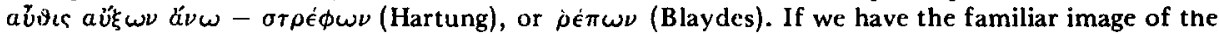
tipping scales, then there is the suggestion that for Oedipus to go up someone else has to go down. In order that he may achieve release and heroization, Polyneikes has to take over his doom, a burden which drags down Antigone also - see lines 1405-46 and 1769-76 at the very end. A note of profound pessimism taints the sublimity of the final scenes of this play.

19. Though Wilamowitz, despite his carlicr stance (sce n.3) thought that they might go back to Menander; sec Das Schicdsgericht (1925)5. There is possibly another exit marked in the margin of Men. Misoumenos 269; see Gomme - Sandbach ad loc. (I owe these references to Dr Colin Austin.)

20. Rutherford 104; cf. Lowe 36, Koster 98; for arguments closer to mine see Russo, Aristofane, 
autore di teatro (1962) 66-74, 299-302, Gelzer RE Supp. xii 1551. For full and uscful discussion of parepigraphai in comedy see Rutherford 101-14, Koster 96-102.

21 Second century A.D., not B.C. as supposed by Dearden, The stage of Aristophanes (1976) 184 n.3. For discussion see Koster.

22. The precise text of both lines is open to dispute. 